\title{
AN AUTOMATED PYTHON BASED TOOL TO DETERMINE EQUILIBRIUM CONSTANTS (K) OF GASEOUS PHASE REACTIONS
}

\author{
Somen Jana \\ Department of Chemical Engineering, \\ Banasthali Vidyapith, Rajasthan, India
}

\begin{abstract}
Python coding has been applied to determine the $K$ value of gaseous phase reactions from the reactants, products, reaction stoichiometry and reaction temperature by a complex model. The program determined $K$ values has been found sufficiently close to the reported values for seven different reactions at three different temperatures. In the second part of the study, variation of reaction equilibrium constants with temperature has been studied for various industrial gaseous phase reactions such as, methanation reaction, hydrocarbon combustion, production of formaldehyde from methanol, methanol production from syngas and production of ethanol from ethylene around the optimum temperature range of the processes'. The $K$ values have been shown increasing or decreasing trend with the increase of the temperature according to the endothermic or exothermic character of the reactions.
\end{abstract}

Keywords: Equilibrium constant; Python; Gaseous phase reaction; Industrial chemical reactions.

\section{INTRODUCTION}

Reaction equilibrium constant is one of the most important parameter in the field of chemistry and chemical engineering. As, none of the reaction ever goes to completion, from the said parameter, one get an idea about the progress of a reaction in terms of its reactants and products' concentration or partial pressure. If, a gaseous phase reaction can be represented by:

$\left|\gamma_{1}\right| A_{1}+\left|\gamma_{2}\right| A_{2} \leftrightarrow\left|\gamma_{3}\right| A_{3}+\left|\gamma_{4}\right| A_{4}$

The chemical reaction equilibrium constant $(\mathrm{K})$ can be represented by

$$
K=\frac{C_{A_{3}}^{\left|\gamma_{3}\right|} \times C_{A_{4}}^{\left|\gamma_{4}\right|}}{C_{A_{2}}^{\left|\gamma_{2}\right|} \times C_{A_{2}}^{\left|\gamma_{2}\right|}}
$$

Where, $C_{A_{i}}$ represents the concentration of i-th chemical species in equilibrium and $\left|\gamma_{i}\right|$ is the stoichiometric coefficient of $i$-th chemical species. $\gamma_{i}$ is considered as +ve for products and -ve for reactants. [Fogler, 2006; Levenspiel, 1999].

Determination of the values of chemical equilibrium constants $(\mathrm{K})$ for different reactions at different temperature is an old practice in chemical industries. The famous BenesiHildebrand method was proposed in 1949, in which the method for determination of equilibrium constant $(\mathrm{K})$ has been shown using the reaction of iodine and aromatic hydrocarbons by spectrophotometry [Benesi and Hildebrand, 1949]. The process was further modified by different researchers [Rose and Drago, 1959; Exner, 1997; Scott, 1956]. Tang et. al. has determined equilibrium constant for atom transfer radical polymerization using modified Fischer's equations [Venayak et.al., 2019]. Christensen et. al. and Eatough et. al. have publicized detailed description for the determination of equilibrium constant by titration calorimetry using data reduction technique for various kind of reactions [Christensen et. al., 1972; Eatough et. al., 1972]. Further, several researchers, have worked for the determination of reaction equilibrium constants such as, for cyano complexes [Beck, 1987], metal-ion complex [Högfeldt, 1982, Sillén et. al., 1964], fluoride complexes in aquous solutions [Bond and Hefter, 1980] etc. Hummel et. al. have reviewed regarding the availability of the equilibrium constants from different sources [Hummel et. al., 2019].

Determination of chemical equilibrium constant for gaseous phase reactions is also a trend in research. Different researchers have reported the equilibrium data for various reactions. Lau et. al. has found the temperature dependency of equilibrium constant for gaseous phase reaction $\mathrm{H}_{3} \mathrm{O}+\left(\mathrm{H}_{2} \mathrm{O}\right)_{\mathrm{n}-1}$ + water $=\mathrm{H}_{3} \mathrm{O}+\left(\mathrm{H}_{2} \mathrm{O}\right)_{\mathrm{n}}$ [21]. Wenzel and Sundmatcher have established a theoretical method for determination of equilibrium constant for gas-solid reactions [Wenzel and Sundmatcher, 2019]. Glasovac et.al. has reported gas-phase basicities of 7 biguanides using equilibrium and kinetics [Glasovac et.al., 2016]. 


\section{International Journal of Engineering Applied Sciences and Technology, 2020 \\ Vol. 4, Issue 11, ISSN No. 2455-2143, Pages 131-143 \\ Published Online March 2020 in IJEAST (http://www.ijeast.com)}

Many previous attempts were done to determine chemical reaction equilibrium constant using software. Alderighiet.al. has reported a computer programme written on Windows to calculate the equilibrium constants of soluble and partially soluble species [Alderighi, 1999]. Formation constants of complex species in solution has been calculated by a computer programme named Miniquad [Sabatini, 1974]. A combination of 10 programmes entitled HYPERQUAD is applied to determine the equilibrium in solution [Gans, 1996]. Meshkov and Gamov have presented an algorithm for determination of equilibrium constants from UV-vis and potentiometric data [Meshkov and Gamov, 2019]. Paz-García et. al. has described a mathematical model for the determination of multiple species chemical equilibrium based on the extent of reaction using Newton-Raphson method [Paz-García et. al., 2013].

On the other hand, Python is a high level, free-to-use, general purpose programming language used for various scientific fields such as computational physics [Borcherds, 2007], chemistry [Pocasangre and Fujimitsu, 2018], psychology [Peirce, 2007], biotechnology [Venayak, 2019], chemical engineering [Khan et. al., 2019] and many more.
As per the author's knowledge, no specific methodology has been developed for determination of equilibrium constant $(\mathrm{K})$ from standard enthalpies, Gibbs energy and heat capacity data. In this present work, effort has been made to produce a Python based tool for determination of reaction equilibrium constant (K) of gaseous phase reactions from the said properties. Further, the tool has been tested by comparing the model determined values with the reported values of K. Additionally, the values of $\mathrm{K}$ has been determined at different temperatures for the production of methane from synthesis gas, combustion of hydrocarbons, formaldehyde production from methanol, formation of methanol from synthesis gas and production of ethanol from the hydration of ethylene using this tool.

\section{HARDWARE AND SOFTWARE:}

The work was conducted on desktop computer (Intel (R); 2.93 $\mathrm{GHz}$ and 4 GB RAM). The working platform was Windows 10 (Microsoft Corporation) and Python 3.1 was used as the programming language.

\section{METHODS}

\section{A. THEORY:}

The variation of heat capacity $\left(\mathrm{C}_{\mathrm{P}}\right)$ with temperature of a gaseous species can be found from the formula [Smith et. al., 2008]:

$$
\frac{C_{P}}{R}=A+B T+C T^{2}+D T^{-2}
$$

Where, $\mathrm{R}$ is the universal gas constant. The values of A, B, C and D of the gaseous chemical species could be obtained from Table 1 . The data of Table 1 has been adapted from elsewhere [Smith et. al., 2008].

Table 1: Standard enthalpies, Gibbs energy and heat capacity data of components [Smith et. al., 2008]

\begin{tabular}{ccccccc}
\hline \multirow{2}{*}{ Component } & $\begin{array}{c}\text { Standard } \\
\text { enthalpy }\end{array}$ & $\begin{array}{c}\text { Gibbs energy } \\
(\text { Joule/mole) }\end{array}$ & \multicolumn{4}{c}{ Heat Capacity Data } \\
\cline { 5 - 7 } & & & $\mathbf{A}$ & $\mathbf{B}$ & $\mathbf{C}$ & D \\
\hline Hydrogen $\left(\mathrm{H}_{2}\right)$ & 0 & 0 & 3.249 & $4.22 \times 10^{-4}$ & 0 & $8.30 \times 10^{4}$ \\
Oxygen $\left(\mathrm{O}_{2}\right)$ & 0 & 0 & 3.369 & $5.06 \times 10^{-4}$ & 0 & $-2.27 \times 10^{4}$ \\
Water $\left(\mathrm{H}_{2} \mathrm{O}\right)$ & -241818 & -228572 & 3.47 & $1.45 \times 10^{-3}$ & 0 & $1.21 \times 10^{4}$ \\
Nitrogen $\left(\mathrm{N}_{2}\right)$ & 0 & 0 & 3.28 & $5.93 \times 10^{-4}$ & 0 & $4.00 \times 10^{3}$ \\
Ammonia $\left(\mathrm{NH}_{3}\right)$ & -46110 & -16450 & 3.578 & $3.02 \times 10^{-3}$ & 0 & $-1.86 \times 10^{4}$ \\
$\begin{array}{c}\text { Nitric oxide }(\mathrm{NO}) \\
\text { Nitrogen di-oxide }\end{array}$ & 90250 & 86550 & 3.387 & $6.29 \times 10^{-4}$ & 0 & $1.40 \times 10^{3}$ \\
$\quad\left(\mathrm{NO}_{2}\right)$ & 33180 & 51310 & 4.982 & $1.20 \times 10^{-3}$ & 0 & $-7.92 \times 10^{4}$ \\
$\begin{array}{c}\text { Carbon } \\
\text { monoxide }(\mathrm{CO})\end{array}$ & -110525 & -137169 & 3.376 & $5.57 \times 10^{-4}$ & 0 & $-3.10 \times 10^{3}$ \\
$\begin{array}{c}\text { Carbon di-oxide } \\
\left(\mathrm{CO}_{2}\right)\end{array}$ & -393509 & -394359 & 5.457 & $1.05 \times 10^{-3}$ & 0 & $-1.16 \times 10^{5}$
\end{tabular}




\section{International Journal of Engineering Applied Sciences and Technology, 2020 \\ Vol. 4, Issue 11, ISSN No. 2455-2143, Pages 131-143 \\ Published Online March 2020 in IJEAST (http://www.ijeast.com)}

$\begin{array}{ccccccc}\begin{array}{c}\text { Sulfur di-oxide } \\ \left(\mathrm{SO}_{2}\right)\end{array} & -296830 & -300194 & 5.699 & 8.01 \times 10^{-4} & 0 & -1.02 \times 10^{5} \\ \begin{array}{c}\text { Hydrogen di-sulfide } \\ \left(\mathrm{H}_{2} \mathrm{~S}\right)\end{array} & -20630 & -33560 & 3.931 & 1.49 \times 10^{-3} & 0 & -2.32 \times 10^{4} \\ \text { Nitrous oxide }\left(\mathrm{N}_{2} \mathrm{O}\right) & 82050 & 104200 & 5.328 & 1.12 \times 10^{-3} & 0 & -9.28 \times 10^{4} \\ \text { Methane }\left(\mathrm{CH}_{4}\right) & -74520 & -50460 & 1.702 & 9.08 \times 10^{-3} & -2.16 \times 10^{-6} & 0 \\ \text { Formaldehyde } & -108570 & -102530 & 2.264 & 7.02 \times 10^{-3} & -1.88 \times 10^{-6} & 0 \\ \quad(\mathrm{HCHO}) & -200660 & -161960 & 2.211 & 1.22 \times 10^{-2} & -3.45 \times 10^{-6} & 0 \\ \text { Methanol }\left(\mathrm{CH}_{3} \mathrm{OH}\right) & -31855 & 1.131 & 1.92 \times 10^{-2} & -5.56 \times 10^{-6} & 0 \\ \text { Ethane }\left(\mathrm{C}_{2} \mathrm{H}_{6}\right) & -83820 & -24290 & 1.213 & 2.88 \times 10^{-2} & -8.82 \times 10^{-6} & 0 \\ \text { Propane }\left(\mathrm{C}_{3} \mathrm{H}_{8}\right) & -104680 & -16570 & 1.935 & 3.69 \times 10^{-2} & -1.14 \times 10^{-5} & 0 \\ \text { Butane }\left(\mathrm{C}_{4} \mathrm{H}_{10}\right) & -125790 & -168490 & 3.518 & 2.00 \times 10^{-2} & -6.00 \times 10^{-6} & 0 \\ \text { Ethanol }\left(\mathrm{C}_{2} \mathrm{H}_{5} \mathrm{OH}\right) & -235110 & 68460 & 1.424 & 14.39 \times 10^{-3} & -4.39 \times 10^{-6} & 0 \\ \text { Ethylene }\left(\mathrm{C}_{2} \mathrm{H}_{4}\right) & 52510 & 0 & 0 & 0 & 0 & 0 \\ \mathrm{NA} & 0 & & & 0 & 0\end{array}$

Using Equation (3), the sensible heat integral between temperature $\mathrm{T}_{0}$ and $\mathrm{T}$ could be calculated by:

$$
\begin{aligned}
& \int_{T_{0}}^{T} \frac{C_{P}}{R} d T=A T_{0}(\tau-1)+\frac{B}{2} T_{0}^{2}\left(\tau^{2}-1\right)+\frac{C}{3} T_{0}^{3}\left(\tau^{3}-1\right)+\frac{D}{T_{0}}\left(\frac{\tau-1}{\tau}\right) \\
\tau= & \frac{T}{T_{0}}
\end{aligned}
$$

Where,

Now, Equation (4) could be slightly modified to obtain the mean heat capacity between the same temperature limit by:

$$
\frac{1}{T-T_{0}} \int_{T_{0}}^{T} \frac{C_{P}}{R} d T=A+\frac{B}{2} T_{0}(\tau+1)+\frac{C}{3} T_{0}^{2}\left(\tau^{2}+\tau+1\right)+\frac{D}{\tau T_{0}^{2}}-----(5)
$$

As, the standard state specific heat capacity is represented by, $C_{P}^{0}$, the standard heat capacity change during the reaction can be represented by:

$$
\Delta C_{P}^{0}=\sum_{i} \gamma_{i} C_{p i}^{0}
$$

Where, $C_{P i}^{0}$ is the standard state specific heat of $i$-th component.

Now, the change of standard state of enthalpy $\left(d \Delta H^{0}\right)$ can be calculated by:

$$
d \Delta H^{0}=\Delta C_{P}^{0} d T
$$

After integration of Equation (7) between $\mathrm{T}_{0}$ to $\mathrm{T}$ : 


$$
\Delta H^{0}=\Delta H_{0}^{0}+R \int_{T_{0}}^{T} \frac{\Delta C_{P}^{0}}{R}
$$

Where $\Delta H^{0}$ and $\Delta H_{0}^{0}$ are change in heat of reaction at temperature $\mathrm{T}$ and at reference temperature $\mathrm{T}_{0}$ respectively. During the integration of second part of the Equation(8) between $\mathrm{T}_{0}$ and $\mathrm{T}$, using Equation (3), the result will be analog of Equation (4), such as:

Where, by definition,

$$
\begin{gathered}
\int_{T_{0}}^{T} \frac{\Delta C_{P}^{0}}{R} d T=(\Delta A) T_{0}(\tau-1)+\frac{\Delta B}{2} T_{0}^{2}\left(\tau^{2}-1\right)+\frac{\Delta C}{3} T_{0}^{3}\left(\tau^{3}-1\right)+\frac{\Delta D}{T_{0}}\left(\frac{\tau-1}{\tau}\right) \\
\Delta A=\sum_{i} \gamma_{i} A_{i}, \Delta B=\sum_{i} \gamma_{i} B_{i} \quad \Delta C=\sum_{i} \gamma_{i} C_{i} \quad \Delta D=\sum_{i} \gamma_{i} D_{i} .
\end{gathered}
$$

However, the mean change of heat capacity between the same temperature ranges can be calculated using:

$$
\frac{1}{T-T_{0}} \int_{T_{0}}^{T} \frac{\Delta C_{P}^{0}}{R} d T=\Delta A+\frac{\Delta B}{2} T_{0}(\tau+1)+\frac{\Delta C}{3} T_{0}^{2}\left(\tau^{2}+\tau+1\right)+\frac{\Delta D}{\tau T_{0}^{2}}
$$

It can be noted that Equation (10) is analogues to Equation (5)

Further, the entropy change of an ideal gas during the temperature change from $T_{0}$ to $T$ and pressure change from $\mathrm{P}_{0}$ to $\mathrm{P}$ can be represented by:

$$
\frac{\Delta S}{R}=\int_{T_{0}}^{T} \frac{C_{P}^{i g}}{R} \frac{d T}{T}-\ln \frac{P}{P_{0}}
$$

Where, S represents entropy. Using Equation (3), at constant pressure, this equation can be modified to [Smith et. al., 2008]:

$$
\frac{\Delta S}{R}=\int_{T_{0}}^{T} \frac{C_{P}^{i g}}{R} \frac{d T}{T}=A \times \ln \tau+\left[B T_{0}+\left(C T_{0}^{2}+\frac{D}{\tau^{2} T_{0}^{2}}\right)\left(\frac{\tau+1}{2}\right)\right](\tau-1)
$$

Now, applying constant pressure condition on the equation:

$$
d H=T d S+V d P
$$

And using $d H=C_{P} d T$, it can be said:

$$
d S=C_{P} \frac{d T}{T}
$$

Where, H, T, S, V and P represent enthalpy, temperature, entropy, volume and pressure respectively. Now, multiplying the entropy value of each species with stoichiometric number $\left(\gamma_{i}\right)$, summing over all species and entreating the definition of standard entropy change of reaction provide:

$$
d \Delta S^{0}=\Delta C_{P}^{0} \frac{d T}{T}
$$




\section{International Journal of Engineering Applied Sciences and Technology, 2020 \\ Vol. 4, Issue 11, ISSN No. 2455-2143, Pages 131-143 \\ Published Online March 2020 in IJEAST (http://www.ijeast.com)}

This, on integration gives:

$$
\Delta S^{0}=\Delta S_{0}^{0}+R \int_{T_{0}}^{T} \frac{\Delta C_{P}^{0}}{R} \frac{d T}{T}
$$

Where $\Delta S^{0}$ and $\Delta S_{0}^{0}$ are change of entropy at temperature $\mathrm{T}$ and at reference temperature $\mathrm{T}_{0}$ respectively. Now, starting from:

$$
\Delta G^{0}=\Delta H^{0}-T \Delta S^{0}
$$

Where $\Delta G^{0}$ is change of Gibbs energy at standard state. $\Delta H^{0}$ and $\Delta S^{0}$ could be calculated using Equation (8) and Equation (16).Using those, Equation (17)could be modified to:

$$
\Delta G^{0}=\Delta H_{0}^{0}+R \int_{T_{0}}^{T} \frac{\Delta C_{P}^{0}}{R} d T-T \Delta S_{0}^{0}-R T \int_{T_{0}}^{T} \frac{\Delta C_{P}^{0}}{R} \frac{d T}{T} \text {----- (18) }
$$

Again; using $\Delta S_{0}^{0}=\frac{\Delta H_{0}^{0}-\Delta G_{0}^{0}}{T_{0}}$ and dividing the whole equation using RT modifies Equation (18) to:

$$
\frac{\Delta G^{0}}{R T}=\frac{\Delta G_{0}^{0}-\Delta H_{0}^{0}}{R T_{0}}+\frac{\Delta H_{0}^{0}}{R T}+\frac{1}{T} \int_{T_{0}}^{T} \frac{\Delta C_{P}^{0}}{R} d T-\int_{T_{0}}^{T} \frac{\Delta C_{P}^{0}}{R} \frac{d T}{T}
$$

Now, as $\ln K=-\frac{\Delta G^{0}}{R T}$, where $\mathrm{K}$ is the reaction equilibrium constant, it can be said:

$$
-\ln K=\frac{\Delta G_{0}^{0}-\Delta H_{0}^{0}}{R T_{0}}+\frac{\Delta H_{0}^{0}}{R T}+\frac{1}{T} \int_{T_{0}}^{T} \frac{\Delta C_{P}^{0}}{R} d T-\int_{T_{0}}^{T} \frac{\Delta C_{P}^{0}}{R} \frac{d T}{T}
$$

The first integral can be calculated using Equation (10) and second integral can be calculated using Equation (12)

\section{B. COMPUTER PROGRAM:}

As, the theory explained in the Section III (a) is complex in nature, a computer program is needed to executed it with ease. The program is coded in Python 3.1 in such a way that the user will be asked to input the reactants and products of a gaseous phase chemical reaction by the chemical formulae. Provision has been provided to input maximum of 2 reactants and products, whereas, reactions with more numbers of reactants or products also could be executed with small changes in the coding. In case of less than two reactants or products, the user may input "NA", instead of the chemical formula of the second reactant/product. Further, the user will be asked to input the stoichiometric numbers of each reactants and products. Additional, the user need to input the temperature of the reaction in Kelvin. With these input data, the program will evaluate the value of the reaction equilibrium constant of the specific chemical reaction and the value of $\log _{10} \mathrm{~K}$ will be displayed.

$$
\begin{gathered}
\mathrm{CO}+\mathrm{H}_{2} \mathrm{O} \leftrightarrow \mathrm{CO}_{2}+\mathrm{H}_{2}-----(21) \\
\mathrm{NO}+\frac{1}{2} \mathrm{O}_{2} \leftrightarrow \mathrm{NO}_{2}-----(22)
\end{gathered}
$$

The screenshot for the execution of Equation (21) (i.e. a reaction of two reactants and two products) is shown in Figure 1 (a), whereas, Figure 1 (b) representing the implementation of the reaction of two reactants and one product i.e. Equation 


\title{
International Journal of Engineering Applied Sciences and Technology, 2020 \\ Vol. 4, Issue 11, ISSN No. 2455-2143, Pages 131-143 \\ Published Online March 2020 in IJEAST (http://www.ijeast.com)
}

(22).

Input 1st REACTANT (Formula in Capital Letters) $\ldots$
Input 2nd REACTANT (Formula in Capital Letters) $\ldots$
Enter the stoichiometric coeffecient of 1 st REACTANT $\ldots$
Enter the stoichiometric coeffecient of 2nd REACTANT $\ldots$
Input 1st PRODUCT (Formula in Capital Letters) $\ldots$
Input 2nd PRODUCT (Formula in Capital Letters) $\ldots$.
Enter the stoichiometric coeffecient of 1 st PRODUCT $\ldots$
Enter the stoichiometric coeffecient of 2 nd PRODUCT $\ldots$
Input the initial temperature (In Kelvin) ... 600
The value of log Kp is $=1.5004517259568275$

Figure 1 (a). Screenshot during the execution of Equation (21), reaction of two reactants and two products.

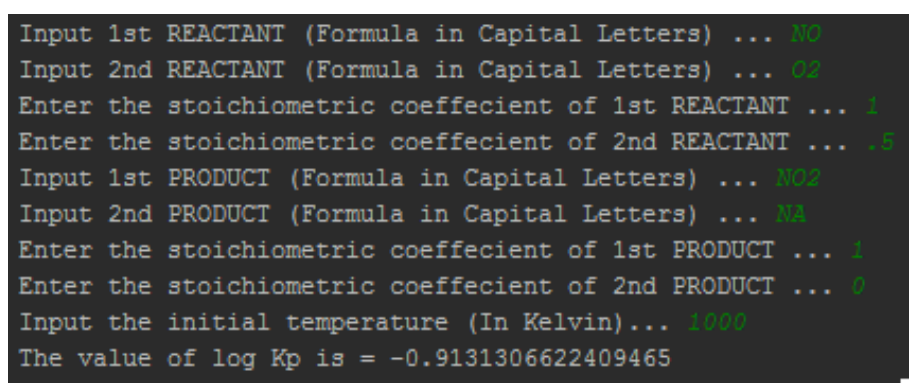

\section{$\underline{\text { Algorithm - } 1}$}

\author{
Step 1 Start \\ Step 2 Input: Reactants as react1 \& react2 \\ Input: Products as prod $1 \& \operatorname{prod} 2$ \\ Input: Stoichiometric coefficients as gamma_react1, gamma_react2, gamma_prod1 \& \\ gamma_prod2 \\ Input: Temperature of reaction in Kelvin as temp \\ Step 3 Repeat this step for RowNumber from 1 to 21: \\ If $\quad$ react $1==$ Value of Table 1 (row= RowNumber, Column=1) \\ h1= Value of Table 1 (row= RowNumber, Column=2) \\ $\mathrm{g} 1=$ Value of Table 1 (row= RowNumber, Column=3) \\ a1= Value of Table 1 (row= RowNumber, Column=4) \\ $\mathrm{b} 1=$ Value of Table 1 (row= RowNumber, Column=5) \\ $\mathrm{c} 1=$ Value of Table 1 (row= RowNumber, Column=6) \\ $\mathrm{d} 1=$ Value of Table 1 (row= RowNumber, Column=7) \\ Step 4 Repeat this step for RowNumber from 1 to 21: \\ If $\quad$ react $2==$ Value of Table 1 (row $=$ RowNumber, Column=1) \\ h2= Value of Table 1 (row= RowNumber, Column=2) \\ g2= Value of Table 1 (row= RowNumber, Column=3) \\ a2 $=$ Value of Table 1 (row= RowNumber, Column=4) \\ $\mathrm{b} 2=$ Value of Table 1 (row $=$ RowNumber, Column=5) \\ $\mathrm{c} 2=$ Value of Table 1 (row $=$ RowNumber, Column=6) \\ $\mathrm{d} 2=$ Value of Table 1 (row= RowNumber, Column=7) \\ Step 5 Repeat this step for RowNumber from 1 to 21: \\ If $\operatorname{prod} 1==$ Value of Table $1($ row $=$ RowNumber, Column=1) \\ h3= Value of Table 1 (row= RowNumber, Column=2) \\ g3= Value of Table 1 (row= RowNumber, Column=3) \\ a3 = Value of Table 1 (row= RowNumber, Column=4) \\ b3 = Value of Table 1 (row= RowNumber, Column=5)
}


International Journal of Engineering Applied Sciences and Technology, 2020

Vol. 4, Issue 11, ISSN No. 2455-2143, Pages 131-143

Published Online March 2020 in IJEAST (http://www.ijeast.com)

c3 $=$ Value of Table 1 (row= RowNumber, Column=6)

$\mathrm{d} 3=$ Value of Table 1 (row= RowNumber, Column=7)

Step 6 Repeat this step for RowNumber from 1 to 21:

If $\operatorname{prod} 2==$ Value of Table 1 (row= RowNumber, Column=1)

$\mathrm{h} 4=$ Value of Table 1 (row= RowNumber, Column=2)

g4= Value of Table 1 (row= RowNumber, Column=3)

a4 $=$ Value of Table 1 (row= RowNumber, Column=4)

$\mathrm{b} 4=$ Value of Table 1 (row= RowNumber, Column=5)

c4= Value of Table 1 (row= RowNumber, Column=6)

$\mathrm{d} 4=$ Value of Table 1 (row= RowNumber, Column=7)

Step 7 delH=gamma_prod $2 \times h 4+$ gamma_prod $1 \times h 3$-gamma_react $2 \times h 2$-gamma_react $1 \times h 1$ delG=gamma_prod $2 \times g 4+$ gamma_prod $1 \times g 3$-gamma_react $2 \times g 2$-gamma_react $1 \times g 1$ del_a=gamma_prod $2 \times a 4+g a m m a \_p r o d 1 \times a 3$-gamma_react $2 \times a 2$-gamma_react $1 \times a 1$ del_b=gamma_prod $2 \times b 4+$ gamma_prod $1 \times b 3$-gamma_react $2 \times b 2$-gamma_react $1 \times b 1$ del_c=gamma_prod $2 \times c 4+$ gamma_prod $1 \times$ c3 3 -gamma_react $2 \times$ c2 2 -gamma_react $1 \times 1$ del_d=gamma_prod $2 \times \mathrm{d} 4+$ gamma_prod $1 \times \mathrm{d} 3$-gamma_react $2 \times \mathrm{d} 2$-gamma_react $1 \times \mathrm{d} 1$

Step 8 temp0 $=298.15$

tau=temp/temp0

Step 9 idcph $=($ del_a + del_b $\times \operatorname{temp} 0 \times(\operatorname{tau}+1) / 2+$ del_c $\times \operatorname{temp} 0 \times \operatorname{temp} 0 \times(\operatorname{tau} \times \operatorname{tau}+\operatorname{tau}+1) / 3+$ del_d/tau/temp0/temp0) $\times($ temp - temp0)

idcps $=$ del_a $\times \ln (\operatorname{tau})+($ del_b $\times$ temp0 $+($ del_c $\times$ temp0 0 temp0 + del_d $/$ tau/tau/temp0/temp0 $) \times((t a u+$ 1)/2) $) \times(\operatorname{tau}-1)$

eq_const=exp(-((delG - delH)/8.314/temp0 + delH/8.314/temp + idcph/temp - idcps $))$

Step 10 $\log \mathrm{K}=\log$ (eq_const)

Step 11 Print $\log \mathrm{K}$

Step 12 Stop

In Step 7, delH, delG, del_a, del_b, del_c and del_d variables are delineated according to the definition:

$d e l G=\sum_{i} \gamma_{i} \Delta G_{i}^{0}$ del $H=\sum_{i} \gamma_{i} \Delta H_{i}^{0} \quad \Delta A=\sum_{i} \gamma_{i} A_{i} \quad \Delta B=\sum_{i} \gamma_{i} B_{i} \quad \Delta C=\sum_{i} \gamma_{i} C_{i} \quad \Delta D=\sum_{i} \gamma_{i} D_{i}$ and

Step 8 is used to calculate tau according to: $\tau=\frac{T}{T_{0}}$. Further, in Step 9, equilibrium constant is calculated rendering to the Equation (20). The first integral is calculated in the variable "idcph" using Equation (10) and the second integral "idcps" using Equation (12). In Step 10 and Step 11, the value of $\log _{10} \mathrm{~K}$ has been calculated and displayed. Finally, in Step 12, the program is terminated.

IV. RESULT AND DISCUSSION:

\section{A. VALIDATION OF THE PROCESS/COMPUTER PROGRAM:}

In this part of the study, equilibrium constants of seven different reactions were determined at three different temperatures viz. 2000 $\mathrm{K}, 1500 \mathrm{~K}$ and $800 \mathrm{~K}$ using the coded computer program. Further, the found values are compared with the experimental values of reaction equilibrium constant for the same reactions at same temperatures. The experimental values are collected from some other source [Fogler, 2006]. The result is reported in Table 2. It was found that the deviations between the determined and reported values are between 0.11 and 0.1 . The results prove the validity of the model. 


\section{International Journal of Engineering Applied Sciences and Technology, 2020 \\ Vol. 4, Issue 11, ISSN No. 2455-2143, Pages 131-143 \\ Published Online March 2020 in IJEAST (http://www.ijeast.com)}

Table 2: Comparison of calculated and reported values of $\mathrm{K}$ at different temperatures.

\begin{tabular}{|c|c|c|c|c|}
\hline $\begin{array}{l}\text { Sl. } \\
\text { No. }\end{array}$ & Reaction & $\begin{array}{c}\text { Temperature } \\
\text { (K) }\end{array}$ & $\begin{array}{c}\text { Reported Values oflog }(\mathbf{K}) \\
\text { [Fogler] }\end{array}$ & $\begin{array}{c}\text { Calculated Values of } \\
\log (K)\end{array}$ \\
\hline \multirow{4}{*}{01} & \multirow{3}{*}{$\mathrm{CO}+0.5 \mathrm{O}_{2} \leftrightarrow \mathrm{CO}_{2}$} & 2000 & 2.9 & 2.95 \\
\hline & & 1500 & 5.7 & 5.37 \\
\hline & & 800 & 13.3 & 13.94 \\
\hline & \multirow{3}{*}{$\mathrm{SO}_{2}+3 \mathrm{H}_{2} \leftrightarrow \mathrm{H}_{2} \mathrm{~S}+2 \mathrm{H}_{2} \mathrm{O}$} & 2000 & 0.97 & 0.83 \\
\hline \multirow{3}{*}{02} & & 1500 & 3.5 & 2.89 \\
\hline & & 800 & 9.4 & 9.88 \\
\hline & \multirow{3}{*}{$\mathrm{CO}+\mathrm{H}_{2} \mathrm{O} \leftrightarrow \mathrm{CO}_{2}+\mathrm{H}_{2}$} & 2000 & -0.6 & -0.52 \\
\hline \multirow[t]{3}{*}{03} & & 1500 & -0.3 & -0.29 \\
\hline & & 800 & 0.6 & 0.70 \\
\hline & \multirow{3}{*}{$\mathrm{NO}+0.5 \mathrm{O}_{2} \leftrightarrow \mathrm{NO}_{2}$} & 2000 & -2.4 & -2.39 \\
\hline \multirow[t]{3}{*}{04} & & 1500 & -1.8 & -1.91 \\
\hline & & 800 & -0.2 & -0.16 \\
\hline & \multirow{3}{*}{$0.5 N_{2}+1.5 H_{2} \leftrightarrow N_{3}$} & 2000 & -4.8 & -4.93 \\
\hline \multirow[t]{3}{*}{05} & & 1500 & -4.2 & -4.42 \\
\hline & & 800 & -2.7 & -2.64 \\
\hline & \multirow{3}{*}{$\mathrm{NO}+0.5 \mathrm{~N}_{2} \leftrightarrow \mathrm{N}_{2} \mathrm{O}$} & 2000 & -4.3 & -4.28 \\
\hline \multirow[t]{3}{*}{06} & & 1500 & -4.2 & -4.24 \\
\hline & & 800 & -4.0 & -4.03 \\
\hline & \multirow{3}{*}{$0.5 \mathrm{~N}_{2}+0.5 \mathrm{O}_{2} \leftrightarrow \mathrm{NO}$} & 2000 & -1.7 & -1.64 \\
\hline \multirow[t]{2}{*}{07} & & 1500 & -2.5 & -2.44 \\
\hline & & 800 & -5.1 & -5.21 \\
\hline
\end{tabular}

nature, thus, the progress of the reactions towards product side will be retarded at higher temperatures, which in consequence

\section{B. EQUILIBRIUM CONSTANT FOPR METHANATION} REACTION:

Methane is a colorless, odorless gas mostly used as a fuel. It could be produced from $\mathrm{CO}$ or $\mathrm{CO}_{2}$ through hydrogenation under nickel based catalysts. The reactions are as follows:

$$
\begin{aligned}
\mathrm{CO}+3 \mathrm{H}_{2} & \leftrightarrow \mathrm{CH}_{4}+\mathrm{H}_{2} \mathrm{O} \\
\mathrm{CO}_{2}+4 \mathrm{H}_{2} & \leftrightarrow \mathrm{CH}_{4}+2 \mathrm{H}_{2} \mathrm{O}
\end{aligned}
$$

The reactions are favorable in the range of $550 \mathrm{~K}$ to $750 \mathrm{~K}$ [Cheng et. al., 2017]. Thus, in this study, the reaction equilibrium constants for the production of methane from $\mathrm{CO}$ and $\mathrm{CO}_{2}$ are studied between $550 \mathrm{~K}$ and $800 \mathrm{~K}$. The results are shown in Figure 2. It was found that, the value of equilibrium constants $(\mathrm{K})$ decreases with the increase of the temperature for both of the reactions. The value of $\log _{10} \mathrm{~K}$ has been decreased from the value of 7.1 to 1.7 during the increment of the temperature from $570 \mathrm{~K}$ to $780 \mathrm{~K}$ for the Equation (23). Another observation is that, the $\mathrm{K}$ value for the reaction represented by Equation (23) is higher than the $\mathrm{K}$ value for the reaction represented by Equation (24) for same temperature. For $700 \mathrm{~K}$, the value of $\log _{10} \mathrm{~K}$ has been found as 3.4 and 2.4 for Equation (23) and Equation (24) respectively. Both of these phenomena could be explained by LeChatelier's principle. As the both of the reactions are exothermic in [Levenspiel, 1999]. Sehestedet.al. has also reported same type of observations during the methanation of carbon monoxide under nickel catalyst [Sehested et. al., 2005].

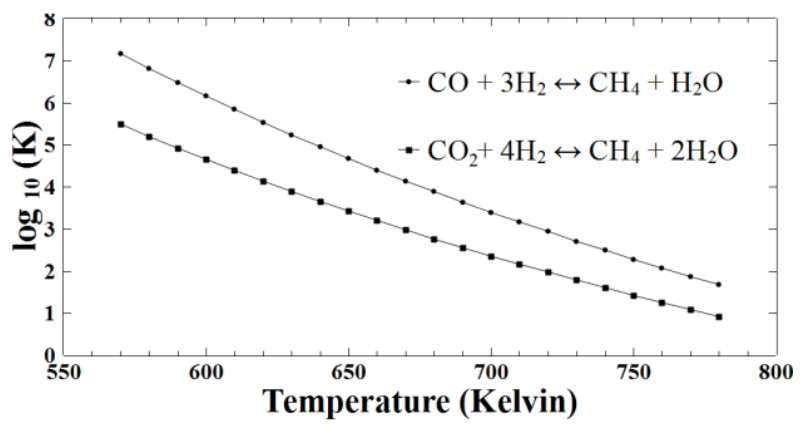

Figure 2. Variation of $\log _{10} \mathrm{~K}$ for the methanation reactions w.r.t. temperature.

\section{B. EQULILIRIUM CONSTANT FOR HYDROCARBON COMBUSTION:}

Combustion of lower chain hydrocarbon for obtaining energy is an old practice for human civilization. But, reaction kinetics and equilibrium constant of such reactions are needed for various scientific calculations, such as the design and application of IC engines [Olikara and Borman, 1975]. Here, 
an effort has been made to find the reaction equilibrium constants for the combustion of four lower chain hydrocarbons, viz. methane, ethane, propane and butane for the wide temperature range of $0{ }^{\circ} \mathrm{C}(373 \mathrm{~K})$ to $1000{ }^{\circ} \mathrm{C}(1373$ $\mathrm{K})$. It was found that, for propane and butane, the values of equilibrium constant approaches infinity below $353 \mathrm{~K}$ and 473 $\mathrm{K}$ respectively. Thus for such cases, the $\mathrm{K}$ values were found for the rest of the range.

The data were intrigued in Figure 3. It was seen that, the value of equilibrium constants decrease w.r.t. the increase of the temperature for all of the alkanes. For methane, the value of $\log _{10} \mathrm{~K}$ has been decreased from a value of 153.3 to 32.9 during the increment of the temperature from $373 \mathrm{~K}$ to 1373
$\mathrm{K}$. This incident could be explained in the light of Le Chatelier's principle as all of the reactions are exothermic in nature. Same kind of trend were reported by other researchers [Wagman et. al., 1945]. Another observation is that, for the same temperature, the value of equilibrium constant increases with the carbon number in the hydrocarbon chain. At a particular temperature of $673 \mathrm{~K}$, the value of $\log _{10} \mathrm{~K}$ has been determined as $62.2,113.6,164.2$ and 214.8 for methane $\left(C_{1}\right)$, ethane $\left(\mathrm{C}_{2}\right)$, propane $\left(\mathrm{C}_{3}\right)$ and butane $\left(\mathrm{C}_{4}\right)$ respectively. This happens because of the gradual increase in the enthalpy of combustion reactions with the increase of the carbon number in the hydrocarbon. Westbrook and Dryer have reported same kind of tendency during the oxidation of hydrocarbon fuels [Westbrook and Dryer, 1981].
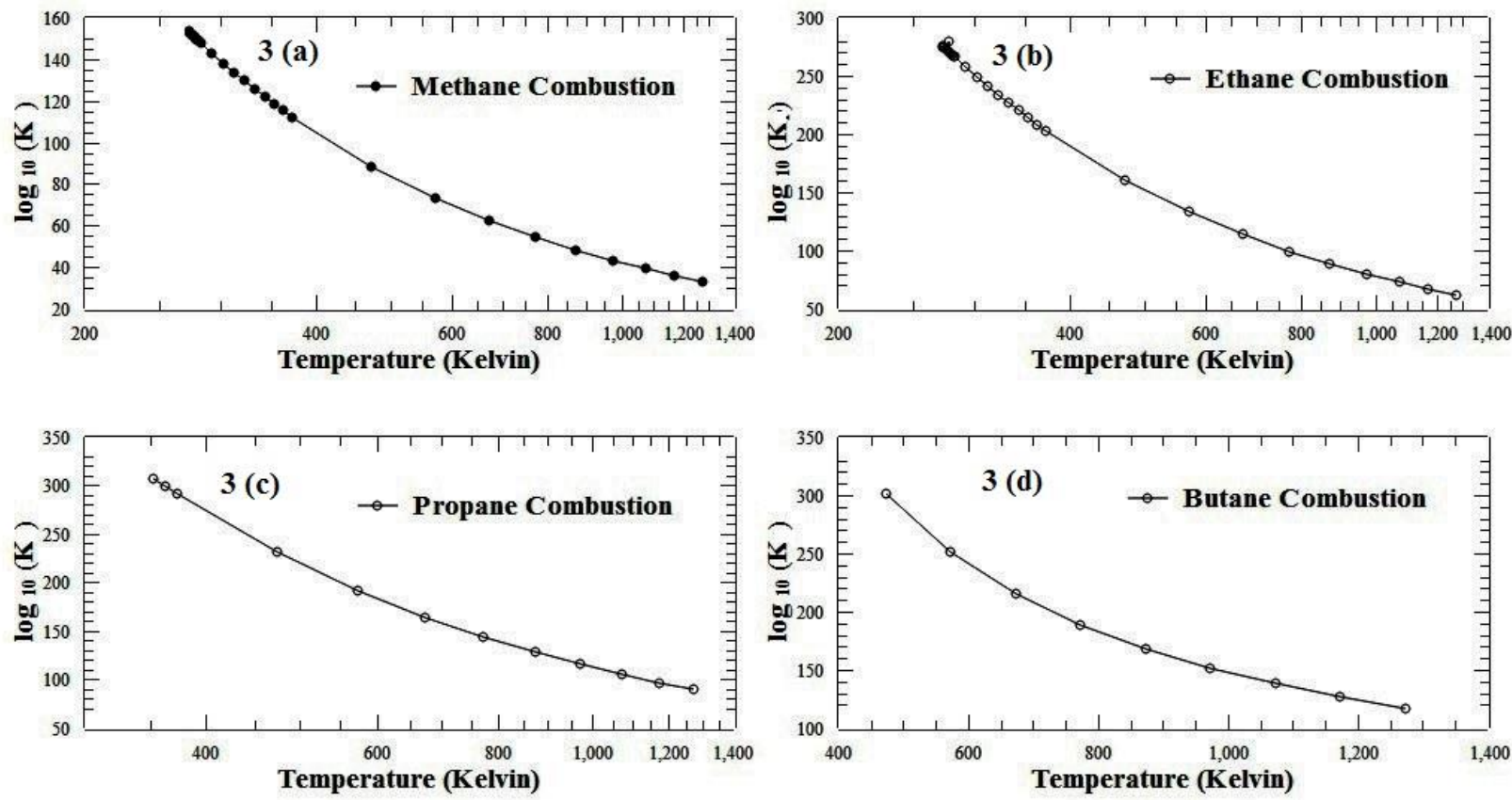

Figure 3. Variation of equilibrium constants w.r.t temperature for the combustion of (a): Methane (b) Ethane (c) Propane (d): Butane.

\section{EQUILIBRIUM CONSTANT FOR PRODUCTION OF FORMALDEHYDE FROM METHANOL:}

Formaldehyde is applicable in the production of vaccine, antiinfective drugs, resin, paint, polymer etc. One of the routes for production of formaldehyde is the pyrolytic decomposition of methanol. This process is mostly conducted by two different reactions viz:

$$
\mathrm{CH}_{3} \mathrm{OH}+\frac{1}{2} \mathrm{O}_{2} \leftrightarrow \mathrm{HCHO}+\mathrm{H}_{2} \mathrm{O}-----
$$

$$
\mathrm{CH}_{3} \mathrm{OH} \leftrightarrow \mathrm{HCHO}+\mathrm{H}_{2}-----(26)
$$

Equation (25) represents the formox process which is conducted under iron and molybdenum or vanadium oxides catalyst at a temperature range of $523 \mathrm{~K}$ to $673 \mathrm{~K}$. On the other hand, Equation (26) is conducted between $788 \mathrm{~K}$ and $823 \mathrm{~K}$ under silver based catalyst [Bahmanpour et. al., 2014]. Thus the variation of reaction equilibrium constant $(\mathrm{K})$ for this first reaction is studied between $500 \mathrm{~K}$ and $700 \mathrm{~K}$ and the second process is studied between $750 \mathrm{~K}$ and $850 \mathrm{~K}$.

It is observed that, for the reaction represented by Equation (25), the value of equilibrium constant (K) decreases w.r.t. the increase of the temperature. On the contrary; the value of equilibrium constant increases w.r.t. the increase of the temperature for the case of Equation (26). The cause lies in the nature of the reactions. The first reaction is exothermic $\left(\Delta \mathrm{H}_{\mathrm{r}}=-\right.$ 


\section{International Journal of Engineering Applied Sciences and Technology, 2020 \\ Vol. 4, Issue 11, ISSN No. 2455-2143, Pages 131-143 \\ Published Online March 2020 in IJEAST (http://www.ijeast.com)}

$159 \mathrm{~kJ} / \mathrm{mol})$ and the second reaction is endothermic $\left(\Delta \mathrm{H}_{\mathrm{r}}=84\right.$ $\mathrm{kJ} / \mathrm{mol}$ ) in nature [Bahmanpour et. al., 2014]. For the exothermic reactions, high temperature hinders the progress of the reaction in the product side which ultimately decreases the value of $\mathrm{K}$. However, the $\mathrm{K}$ value for endothermic reaction

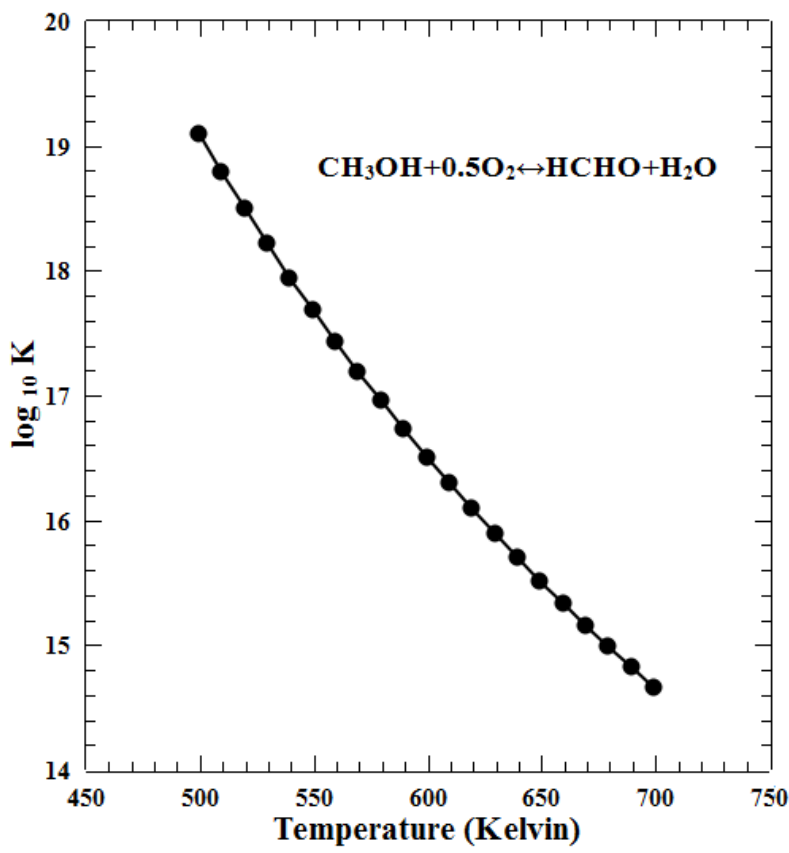

Figure 4 (a). Variation of $\log _{10} \mathrm{~K}$ w.r.t. temperature for Equation (25).

\section{D. $K$ VALUE FOR PRODUCTION OF METHANOL BY HYDROGENATION OF CO:}

Methanol or methyl alcohol $\left(\mathrm{C}_{\mathrm{H} 3} \mathrm{OH}\right)$ is used for the production of many important chemicals viz., acetic acid, formaldehyde, hydrocarbons, etc or it could be directly used as a fuel. A main pathway for production of methanol is the hydrogenation of carbon monoxide. The process is conducted around $250{ }^{\circ} \mathrm{C}(523 \mathrm{~K})$ under alumina supported copper and zinc oxide. The chemical reaction of this process is as follows: [Lee, 1989].

$$
\mathrm{CO}+\mathrm{H}_{2} \leftrightarrow \mathrm{CH}_{3} \mathrm{OH}\left(\Delta \mathrm{H}_{\mathrm{R}}=-90135 \mathrm{~J} / \mathrm{mole}\right)
$$

The trend of $\mathrm{K}$ value has been determined between $450 \mathrm{~K}$ and $600 \mathrm{~K}$ perceiving the optimum temperature. The observation is exhibited in Figure 5 (a).It is observed that the value of $K$ decreased w.r.t. the increase of the temperature. The value of increases over the increment of the reaction temperature. Same kind of trend was found by other researchers during the methanol oxidation with air under molybdenum catalyst [Adkins and Peterson, 1931]. The result is displayed in Figure 4 (a) and 4 (b).

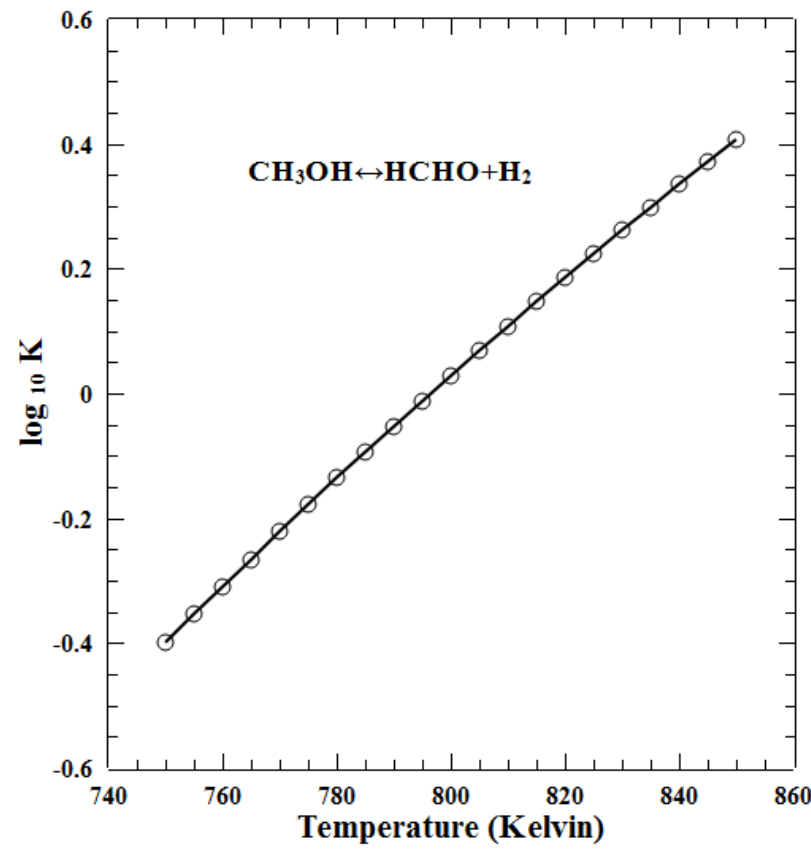

Figure 4 (b). Variation of $\log _{10} \mathrm{~K}$ w.r.t. temperature for Equation (26).

$\log _{10} \mathrm{~K}$ has been decreased from a value of -1.17 at $450 \mathrm{~K}$ to a value of -4.04 at $600 \mathrm{~K}$. The fact could be explained by the fact that the reaction is exothermic in nature. Same kind of trend has been observed by Agny and Takoudls during the synthesis of methanol from syngas using a mixture of zinc and copper oxide catalyst [Agny and Takoudls, 1985].

\section{E. K VALUE FOR PRODUCTION OF ETHANOL BY ETHYLENE HYDRATION:}

Ethanol is an alcohol is well known for its anti-microbial properties and its use as a fuel. One of the paths for production of it is the hydration of ethylene. According to Robert A. Britton, the process can be conducted under acidic medium. The optimum temperature range is $530{ }^{\circ} \mathrm{F}(550 \mathrm{~K})$ to $600{ }^{\circ} \mathrm{F}$ $(589 \mathrm{~K})$. The chemical equation of the process is as follows [Borcherds, 2007]:

$\mathrm{C}_{2} \mathrm{H}_{4}+\mathrm{H}_{2} \mathrm{O} \leftrightarrow \mathrm{C}_{2} \mathrm{H}_{5} \mathrm{OH}\left(\Delta \mathrm{H}_{r}=-45792 \mathrm{~J} / \mathrm{mole}\right)$ ------ (28) 
This process is studied between $550 \mathrm{~K}$ and $600 \mathrm{~K}$. The value of $\log _{10} \mathrm{~K}$ has been decreased gradually. The value has been decreased from -2.2 to -2.6 during the increment of the temperature from $550 \mathrm{~K}$ to $600 \mathrm{~K}$. Reviewers have been found

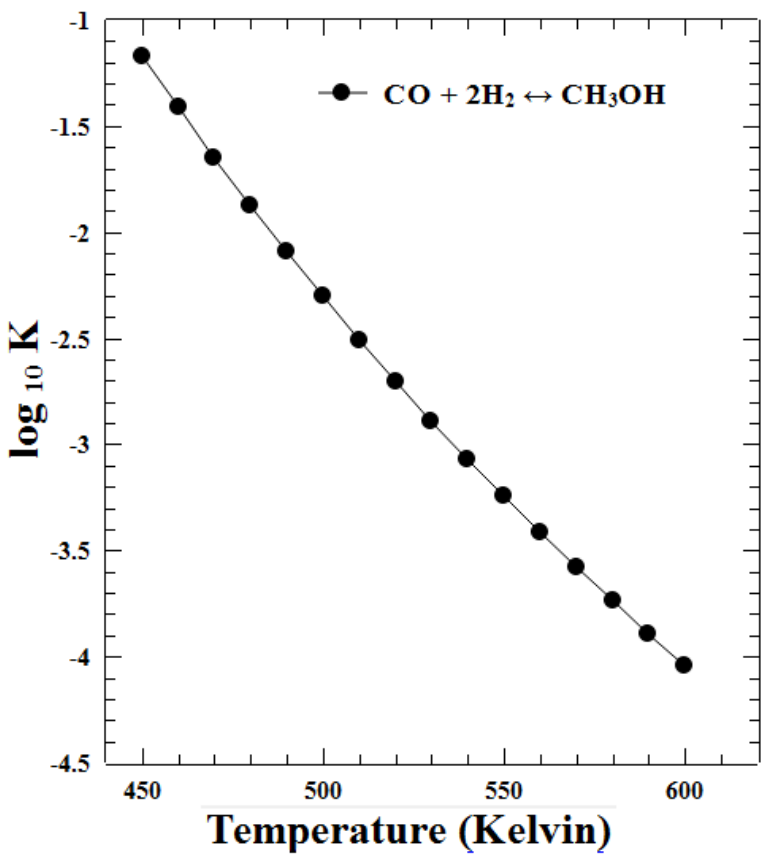

Figure 5 (a). Variation of $\log _{10} \mathrm{~K}$ w.r.t. temperature for methanol production by hydrogenation of $\mathrm{CO}$. the same trend for the industrial processes in different publications [Hidzir et. al., 2014]. The trend is depicted in Figure 5 (b).

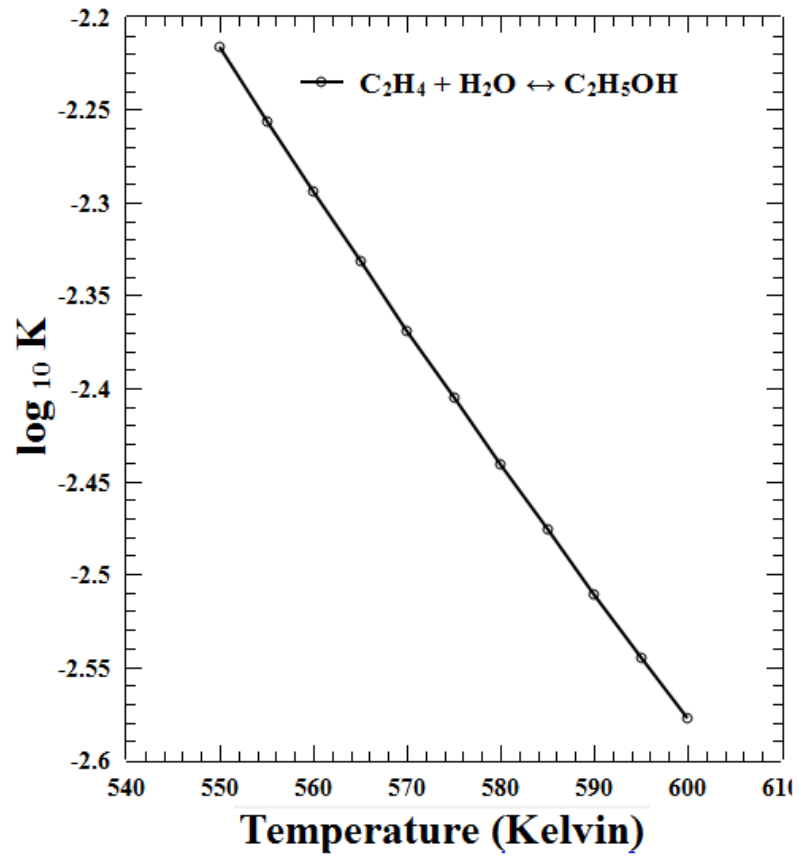

Figure 5 (b). Variation of $\log _{10} \mathrm{~K}$ w.r.t. temperature for ethanol production by hydration of ethanol.

In the same way, $\mathrm{K}$ values for other industrial/chemical processes also could be determined.

\section{CONCLUSION:}

A Python based tool has been prepared to determine the reaction equilibrium constant $(\mathrm{K})$ for gaseous phase reactions. The tool consists of user-friendly interface and very easy-touse. After inputting the reactants, products, stoichiomentric coefficients and the reaction temperature, the program automatically searches the database for the standard enthalpy, Gibbs energy and heat capacity data. Further, the value of $\mathrm{K}$ is determined and displayed. The program determined $\mathrm{K}$ values has been compared with the reported values of $\mathrm{K}$ for different reactions at different temperatures. The obtained results are enough close to the reported data which proves the significance of the programmed tool. Further, the tool has been applied to determine the $\mathrm{K}$ values for different gaseous phase industrial reactions. The variations of $K$ value for these reactions w.r.t. temperature are also studied. $\mathrm{K}$ values of methanation reaction and hydrocarbon combustion has been found to be decreased with the increase of the temperature. Two different reactions for the production of formaldehyde from methanol has shown decreasing and increasing trend according to their exothermic and endothermic nature. Equilibrium constants for the production of methanol from syngas and production of ethanol by the hydration of ethylene also shown decreasing trend w.r.t. the increase of temperature.

\section{REFERENCES:}

[1] Adkins H., and Peterson W.R. (1931). The oxidation of methanol with air over iron, molybdenum, and ironmolybdenum oxides, J Am. Chem. Soc. 53, (pp. 15121520). https://doi.org/10.1021/ja01355a050.

[2] Agny, R.M., Takoudls, C.G., (1985). Synthesis of Methanol from Carbon Monoxide and Hydrogen over a Copper-Zinc Oxide-Alumina Catalyst. Ind. Eng. Chem. Prod. Res. Dev. 24, (pp. 50-55). https://doi.org/10.1021/i300017a010.

[3] Alderighi, L., Gans, P., Ienco, A., Peters, D., Sabatini, A., Vacca, A., (1999). Hyperquad simulation and speciation (HySS): a utility program for the 
International Journal of Engineering Applied Sciences and Technology, 2020

Vol. 4, Issue 11, ISSN No. 2455-2143, Pages 131-143

Published Online March 2020 in IJEAST (http://www.ijeast.com)

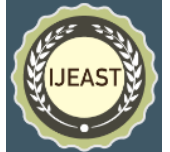

investigation of equilibria involving soluble and partially soluble species. Coordin. Chem. Rev. 184, (pp. 311-318). $\quad$ https://doi.org/10.1016/S00108545(98)00260-4.

[4] Bahmanpour, A.M., Hoadley, A., Tanksale, A. (2014). Critical review and exergy analysis of formaldehyde production processes. Rev Chem Eng. 30, (pp. 583604). https://doi.org/10.1515/revce-2014-0022.

[5] Beck, M.T., (1987). Critical survey of stability constants of cyano complexes. Pure and Applied Chemistry. $59, \quad$ (pp. 1703-1720). http://dx.doi.org/10.1351/pac198759121703.

[6] Benesi, H.A., Hildebrand, J.H., (1949). A spectrophotometric investigation of the interaction of iodine with aromatic hydrocarbons, J. Am. Chem. Soc.71, (pp. 2703-2707). https://doi.org/10.1021/ja01176a030.

[7] Bond, A.M., Hefter, G.T., (1980). Critical Survey of Stability Constants and Related Thermodynamic Data of Fluoride Complexes in Aqueous Solutions. Pergamon Press, Oxford, UK. https://doi.org/10.1002/bbpc.198200026.

[8] Borcherds, P.H., (2007). Python: a language for computational physics. Comp. Phys. Comm.177, (pp. 199-201). https://doi.org/10.1016/j.cpc.2007.02.019.

[9] Britton, R.A., (1972). Direct hydration of ethylene to ethanol. US Patent, US3686334A.

[10] Cheng, C., Shen, D., Xiao, R., Wub, C., (2017). Methanation of syngas $\left(\mathrm{H}_{2} / \mathrm{CO}\right)$ over the different $\mathrm{Ni}$ based catalysts. Fuel. 189, (pp. 419-427). https://doi.org/10.1016/j.fuel.2016.10.122.

[11] Christensen, J.J., Ruckman, J., Eatough, D.J., Izatt, R.M., (1972). Determination of equilibrium constants by titration calorimetry: Part I. Introduction to titration calorimetry. Thermochimica Acta. 3, (pp. 203-218). https://doi.org/10.1016/0040-6031(72)85030-5.

[12] Eatough, D.J., Christensen, J.J., Izatt R.M., (1972). Determination of equilibrium constants by titration calorimetry: Part II. Data reduction and calculation techniques. Thermochimica Acta. 3, (pp. 209-232). https://doi.org/10.1016/0040-6031(72)85031-7.

[13] Exner, O., (1997). Calculating equilibrium constants from spectral data: reliability of the Benesi-Hildebrand method and its modifications. Chemometrics and Intelligent Laboratory Systems. 39, (pp. 85-93). https://doi.org/10.1016/S0169-7439(97)00057-9.

[14] Fogler, S.C., (2006). Elements of Chemical Reaction Engineering, fourth ed. Prentice Hall, USA.

[15] Gans, P., Sabatini, A., Vacca, A., (1996). Investigation of equilibria in solution. Determination of equilibrium constants with the HYPERQUAD suite of programs. 43, (pp. 1739-1753). https://doi.org/10.1016/00399140(96)01958-3.

[16] Glasovac, Z., Eckert-Maksić, M., Kaljurand, I., Saame, J., Leito, I., (2019). Gas phase basicity of biguanides -
Comparison of the equilibrium and the kinetic methods. Inter. J. Mass Spectro. 435, (pp. 48 -61). https://doi.org/10.1016/j.ijms.2018.10.010.

[17] Hidzir, N.S., Som, A.M., Abdullah, Z., (2014). Ethanol Production via Direct Hydration of Ethylene: A review. International conference on global sustainability and chemical engineering (ICGSE), 2014.

[18] Högfeldt, E., (1982). Stability Constants of Metal-ion Complexes. Part A. Inorganic Ligands. IUPAC Chem. Data Series No. 21. Pergamon Press, Oxford, UK. https://doi.org/10.1002/bbpc.19830871236.

[19] Hummel, W., Filella, M., Rowland, D., (2019). Where to find equilibrium constants? Science of the Total Environment. 692, (pp. 49-59). https://doi.org/10.1016/j.scitotenv.2019.07.161.

[20] Khan, Z.A., Tranter, T., Agnaou, M., Elkamel, A., Gostick, J., (2019). Dual network extraction algorithm to investigate multiple transport processes in porous materials: Image-based modeling of pore and grain scale processes. Comp. \& Chem. Engg. 123, (pp. 6477). https://doi.org/10.1016/j.compchemeng.2018.12.025.

[21] Lau, Y.K., Ikuta, S., Kebarle, P., (1982). Thermodynamics and kinetics of the gas-phase reactions $\mathrm{H}_{3} \mathrm{O}+\left(\mathrm{H}_{2} \mathrm{O}\right)_{\mathrm{n}-1}+$ water $=\mathrm{H}_{3} \mathrm{O}+\left(\mathrm{H}_{2} \mathrm{O}\right)_{\mathrm{n}}$. 104, (pp. 1462-1469). https://doi.org/10.1021/ja00370a002.

[22] Lee, S., (1989). Methanol synthesis technology, first ed. CRC Press, Florida.

[23] Levenspiel, O., (1999). Chemical Reaction Engineering, third ed. John Wiley \& Sons, Inc., USA.

[24] Meshkov, A.N., Gamov, G.A., (2019). KEV: A free software for calculating the equilibrium composition and determining the equilibrium constants using UVVis and potentiometric data. Talanta. 199, (pp. 200205). https://doi.org/10.1016/j.talanta.2019.01.107.

[25] Olikara, C. and Borman, G., (1975). A Computer Program for Calculating Properties of Equilibrium Combustion Products with Some Applications to I.C. Engines. SAE Technical Paper. 750468. https://doi.org/10.4271/750468.

[26] Paz-García, J.M., Johannesson, B., Ottosen, L.M., Ribeiro, A.B., Rodríguez-Maroto, J.M., (2013). Computing multi-species chemical equilibrium with an algorithm based on the reaction extents. Comp. \& Chem. Engg. 58, (pp. 135-143). https://doi.org/10.1016/j.compchemeng.2013.06.013.

[27] Peirce, J.W., (2007). PsychoPy-Psychophysics software in Python. J.Neurosc. Meth., 162, (pp. 8-13). https://doi.org/10.1016/j.jneumeth.2006.11.017.

[28] Pocasangre, C., Fujimitsu, Y., (2018). A Python-based stochastic library for assessing geothermal power potential using the volumetric method in a liquiddominated reservoir. Geothermics, 76, (pp. 164-176). https://doi.org/10.1016/j.geothermics.2018.07.009.

[29] Rose, N.J., Drago, R.S., (1959). Molecular Addition 


\section{International Journal of Engineering Applied Sciences and Technology, 2020 \\ Vol. 4, Issue 11, ISSN No. 2455-2143, Pages 131-143 \\ Published Online March 2020 in IJEAST (http://www.ijeast.com)}

Compounds of Iodine. I. An Absolute Method for the Spectroscopic Determination of Equilibrium Constants, J. Am. Chem. Soc. 81, (pp. 6138-6141). https://doi.org/10.1021/ja01532a009.

[30] Sabatini, A., Vacca, A., Gans P., (1974). Miniquad-A general computer programme for the computation of formation constants from potentiometric data. Talanta. 21, (pp. 53-77). https://doi.org/10.1016/00399140(74)80063-9.

[31] Scott, R.L., (1956). Some comments on the Benesi-Hildebrand equation. Recueil des Travaux Chimiques des Pays-Bas, Wiley Online Library. https://doi.org/10.1002/recl.19560750711.

[32] Sehested, J., Dahl, S., Jacobsen, J., Rostrup-Nielsen J.R., (2005). Methanation of $\mathrm{CO}$ over Nickel: Mechanism and Kinetics at High $\mathrm{H}_{2} / \mathrm{CO}$ Ratios. J. Phys. Chem. B. 109, (pp. 2432-2438). https://doi.org/10.1021/jp040239s.

[33] Sillén, L.G., Martell, A.E., Bjerrum, J., (1964). Stability constants of metal-ion complexes. Special publication (Royal Society of Chemistry (Great Britain)), No 17.

[34] Smith, J.M., Van Ness, H.C., Abott, M.M., (2008). Introduction to chemical engineering thermodynamics, eleventh ed. Tata McGraw-Hill, Delhi, India.

[35] Tang, W., Tsarevsky, N.V., Matyjaszewski, K., (2006). Determination of Equilibrium Constants for Atom Transfer Radical Polymerization. J. Am. Chem. Soc. 128, (pp. 1598-1604). https://doi.org/10.1021/ja0558591.

[36] Venayak, N., Raj, K., Mahadevan R., (2019). Impact framework: A python package for writing data analysis workflows to interpret microbial physiology. Metabolic Engg. Comm. $\quad 9, \quad$ e00089. https://doi.org/10.1016/j.mec.2019.e00089.

[37] Wagman, D.D., Kilpatrick, J.E., Taylor, W.J., Pitzer, K.S., Rossini, F.D., (1945). Heats, free energies and equilibrium constants of some reactions involving $\mathrm{O}_{2}$, $\mathrm{H}_{2}, \mathrm{H}_{2} \mathrm{O}, \mathrm{C}, \mathrm{CO}, \mathrm{CO}_{2}$ and $\mathrm{CH}_{4}$. J. Res. Nat. Bureau of Stand. 34, (pp. 143-161).

[38] Wenzel, M., Sundmacher. K., (2019). Derivation of rate equations for equilibrium limited gas-solid reactions. Chem. Engg. Sc. 203, (pp. 76-85). https://doi.org/10.1016/j.ces.2019.03.064.

[39] Westbrook, C.K., Dryer, F.L., (1981). Simplified ReactionMechanisms for the Oxidation of Hydrocarbon Fuels in Flames. Combust. Sci. and Tech.27, (pp. 3143). https://doi.org/10.1080/00102208108946970. 